\title{
II:
}

\section{VARIAÇÃO TEMPORAL DA UMIDADE DO SOLO SOB DIFERENTES COBERTURAS VEGETAIS}

\author{
RETENTION OF SOIL MOISTURE TEMPORAL VARIATION UNDER \\ DIFFERENT VEGETAL COVERS
}

\author{
Rodolfo Alves Barbosa ${ }^{1 *}$ \\ Ronan Soares de Faria ${ }^{1}$ \\ Lucas Jesus da Silveira ${ }^{1}$ \\ Herly Carlos Teixeira Dias ${ }^{1}$ \\ Lucas Veiga Ayres Pimenta ${ }^{1}$ \\ Caetano Marciano de Souza ${ }^{1}$ \\ Andreza Cristina Santiago Ferreira ${ }^{1}$ \\ ${ }^{1}$ Universidade Federal de Viçosa, rodolfo.ufv@gmail.com \\ ronan.soares1987@gmail.com \\ lucas.bugatti@gmail.com \\ herlycarlostdias@gmail.com \\ lucasfip@yahoo.com.br \\ cmsouzaufv@gmail.com \\ santiagoandreza214@gmail.com \\ *Autor para correspondência
}

Artigo submetido em 29/05/2019, aceito em 30/09/2019 e publicado em 23/12/2019.

Resumo: O objetivo foi analisar a capacidade de manutenção da umidade do solo sob diferentes coberturas vegetais (eucalipto, mata nativa e pastagem) em estágio maduro de desenvolvimento em uma bacia hidrográfica na Zona da Mata de Minas Gerais. Três amostras compostas deformadas de solo por parcela foram coletadas nas profundidades de 0-10 e 10-20 cm para análise da matéria orgânica e das propriedades físicas dos solos (textura, porosidade total, densidade de solo e densidade de partículas). A umidade foi monitorada através de amostras de solo, nas profundidades avaliadas, a cada sete dias, durante cinco semanas. O solo sob plantio de eucalipto apresentou os menores valores de densidade de solo e de partículas, em comparação aos solos sob pastagem e mata nativa. A mata nativa apresentou maior contribuição na formação de matéria orgânica do solo (MOS). O eucalipto foi a cobertura vegetal que melhor reteve umidade do solo, seguido da mata nativa e pastagem (eucalipto $>$ mata nativa $>$ pastagem). $\mathrm{O}$ manejo inadequado da pastagem afeta negativamente o conteúdo de matéria orgânica e a capacidade de manutenção da umidade no solo. Plantios de eucalipto, quando bem manejados, favorecem o incremento de matéria orgânica no solo, aumentando a capacidade de retenção de água.

Palavras-chave: Hidrologia Florestal, Manejo de Bacia Hidrográfica, Recursos Hídricos.

Abstract: The aim was to analyze the maintenance capacity of soil moisture under different vegetation covers (Eucalyptus, native forest and pasture) in a mature stage of development in a watershed in the Zona da Mata of Minas Gerais. Three soil-deformed composite samples were collected in the depths of $0-10$ and $10-20 \mathrm{~cm}$ for the analysis of organic matter and soil physical properties (texture, total porosity, soil density and particle density). Moisture was monitored by soil 
samples at the depths evaluated every seven days for five weeks. The soil under Eucalyptus plantation showed the lowest soil and particle density values, compared to soils under pasture and native forest. The native forest showed a greater contribution in the formation of soil organic matter (SOM). Eucalyptus was the vegetation cover that best retained soil moisture, followed by native forest and pasture (Eucalyptus $>$ native forest $>$ pasture). The inadequate management of the pasture negatively affects the organic matter content and the maintenance capacity of soil moisture. Eucalyptus plantations, when well-managed, favor the increment of organic matter in the soil, increasing the water retention capacity.

Keywords: Forest Hydrology, Watershed Management, Water Resources.

\section{INTRODUÇÃO}

A modificação da paisagem com a substituição da vegetação nativa por usos alternativos do solo é um processo que vem se intensificando nas últimas décadas no Brasil, devido à expansão da agricultura e aumento da população (DIAS et al, 2016, BARBOSA et al, 2018; SCHIELEIN, BÖRNER, 2018). Estas mudanças, se realizadas inadequadamente, podem alterar a dinâmica da água dentro da bacia hidrográfica, acarretando na degradação dos solos (NYAMADZAWO et al., 2012; BERTOL et al., 2015; SOUZA-FILHO et al., 2016) e redução na capacidade de infiltração (MARCHINI et al., 2015; LEI e ZHU, 2018).

Secas prolongadas e períodos com enchentes influenciadas por mudanças na disponibilidade de água ao longo do ano tem ocorrido nas últimas décadas, devido as alterações na distribuição temporal das chuvas (ARNEL e GOSLING, 2013; ANA, 2015), acarretando maior vulnerabilidade da população (IPCC, 2015).

A quantidade de água retida no solo após a precipitação é variável com a cobertura existente (VENKATESH et al., 2011; WANG et al., 2013; GASHAW et al., 2018), desenvolvimento da vegetação (HUANG et al., 2016; SUN et al., 2018), exposição solar (GEROY et al., 2011), práticas de manejo adotadas (CARVALHO et al., 2009; JUNIOR et al., 2014; GUADAGNIN et al., 2018) e tipo de solo (BEUTLER et al., 2002; O'GEEN, 2012). Wang et al. (2013) verificaram alterações na dinâmica na umidade do solo sob diferentes coberturas vegetais, onde, com subarbustos apresentando maior retenção da umidade e menor para a plantio de milho.

A manutenção de água no solo favorece o desenvolvimento das plantas e contribui para a recarga de aquíferos (TÁRNIK e IGAZ, 2015), onde o incentivo a adoção de práticas conservacionistas de solo e água são fundamentais para atender a demanda hídrica da população (RICHARDS et al., 2015). A taxa de retenção de água no solo para algumas culturas agrícolas em idades mais avançadas de desenvolvimento ainda é desconhecida. O objetivo deste trabalho foi analisar a capacidade de manutenção da umidade do solo sob diferentes coberturas vegetais em estágio maduro de desenvolvimento em uma bacia hidrográfica.

\section{MATERIAIS E MÉTODOS}

Três locais com diferentes coberturas vegetais, sendo elas: eucalipto, mata nativa e pastagem, localizadas na bacia hidrográfica do Ribeirão São Bartolomeu, no município de Viçosa-MG, com área de $26,76 \mathrm{Km}^{2}$ até a foz, onde é realizada captação de água para a universidade e parte da população da cidade de Viçosa (Figura 1). A delimitação da bacia hidrográfica foi realizada através da obtenção e processamentos de dados do modelo digital de elevação Alos DEM, com resolução espacial de $12,5 \mathrm{~m}$ https://vertex.daac.asf.alaska.edu/ e da geração de um modelo digital de elevação hidrograficamente consisitido reprojetado para sistema de projeção cartográficas 
SIRGAS 2000, zona 23S, utilizando o software ArcGIS 10.4.1.

Figura 1: Bacia Hidrográfica do Ribeirão

São Bartolomeu e localização das amostragens de coberturas do solo próximas à represa de captação de água.

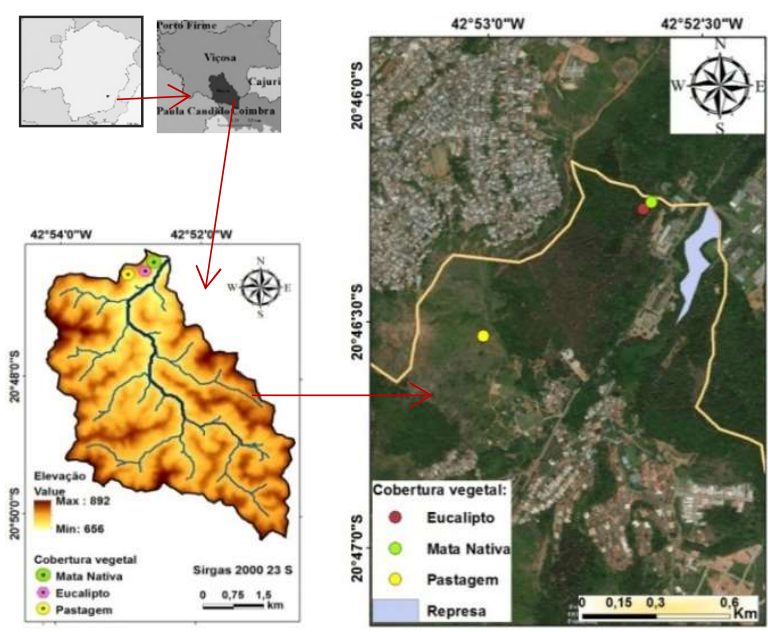

Fonte:Rodolfo Alves

O clima é classificado como Cwa (KÖPPEN, 1900), temperado úmido com inverno seco e verão quente e chuvoso. A precipitação anual média corresponde a $1.361 \mathrm{~mm}$, com distribuição irregular durante o ano, com $83 \%$ da precipitação ocorrendo entre os meses de outubro-março (ALVARES et al., 2013). As temperaturas máxima e mínima anual média são $26,8 \mathrm{e}$ $15,7{ }^{\circ} \mathrm{C}$, respectivamente (SOUZA et al., 2015). Durante o período de coleta das amostras houve uma redução na precipitação (Figura 2).
Figura 2: Precipitação semanal $(1,2,3,4)$ durante os meses de fevereiro a maio de 2016 no local de estudo, em Viçosa, MG.

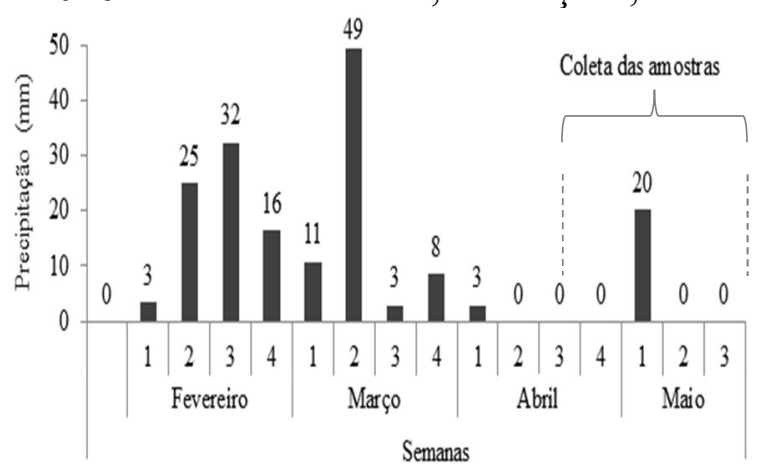

Fonte: Rodolfo Alves Barbosa, LHF-UFV

Três parcelas fixas de $10 \mathrm{~m} \times 10 \mathrm{~m}$ foram demarcadas, sendo uma para cada tipo de cobertura vegetal, para a amostragem dos solos. As parcelas 1, 2 e 3 correspondem às áreas de pastagem, plantio de eucalipto e mata nativa, respectivamente (Tabela 1). Todas as coletas foram realizadas em posição de encosta, com declividade e exposição solar semelhantes em Latossolo Vermelho-Amarelo distrófico.

As parcelas foram subdivididas em 10 transectos de $1 \mathrm{~m}$ de largura por $10 \mathrm{~m}$ de comprimento no sentido da declividade, conforme metodologia proposta por Lorezon et al. (2014). Três transectos foram selecionados aleatoriamente em cada tratamento e o solo tradado nas profundidades de 0-10 e 10-20 cm, assim, 18 amostras de solo foram coletadas por parcela, perfazendo 54 amostras de solo.Nesta parte recomenda-se detalhar os procedimentos envolvidos no desenvolvimento do trabalho a fim de garantir que os leitores consigam interpretar corretamente os resultados ou utilizar as informações para reproduzir o estudo.

$$
\text { Apresenta-se apenas as }
$$
metodologias que darão sustentação aos resultados e às conclusões. Em alguns casos, pode-se subdividir esta seção em tópicos de modo a facilitar a leitura e a identificação de aspectos metodológicos específicos do trabalho em questão. 
Tabela 1: Descrição das parcelas de coberturas vegetais presentes na bacia hidrográfica do Ribeirão São Bartolomeu, em Viçosa, MG.

Mata nativa

Fragmento de Floresta Estacional Semidecidual em estágio médio de sucessão, possuindo 148 espécies e 42 famílias, sendo as famílias Leguminoseae, Euphorbiaceae, Myrtaceae, Lauraceae, Rubiaceae e Flacourtiaceae predominantes no local (FIGUEIREDO et al., 2013). O estrato superior possui predominância das espécies: Copaifera langsdorffii, Xylopia sericea, Luehea grandiflora e Piptadenia gonoacantha; o estrato inferior possui predominância das espécies Siparuna guianensis e Lacistema pubescens. Possui geoforma côncava do solo. A declividade média do local é de $19 \%$.

\section{Eucalipto}

Plantio clonal realizado em março de 2011 de híbrido de Eucalyptus urophylla em espaçamento $3 \times 3 \mathrm{~m}$, com aplicação de fosfato reativo $+120 \mathrm{~g} /$ planta de $\mathrm{N}: \mathrm{P}: \mathrm{K}(6: 30: 6)+$ micronutrientes e duas adubações de cobertura aos 40 dias e 1 ano após o plantio, controle de formigas com Sulfluramida; primeira rotação do povoamento; sem desbaste ou desrama; dap médio de 19,3 cm e altura média das árvores de 25, 9; presença de copa e serapilheira no solo; geoforma côncava do solo. O local possui $21 \%$ de declividade média.

\section{Pastagem}

Pastagem degradada, com ausência de manejo, recorrência de incêndios e predomínio de cobertura das gramíneas Mellinis minutiflora e Brachiaria decumbens (ROMANOVSKI, 2001); área inutilizada pelos proprietérios devido interferência antrópica de não-proprietários através do trânsito entre bairros via trilhas, soltura de animais (equino e gado). O solo possui geoforma côncava. A declividade média do local de amostra foi $18 \%$.
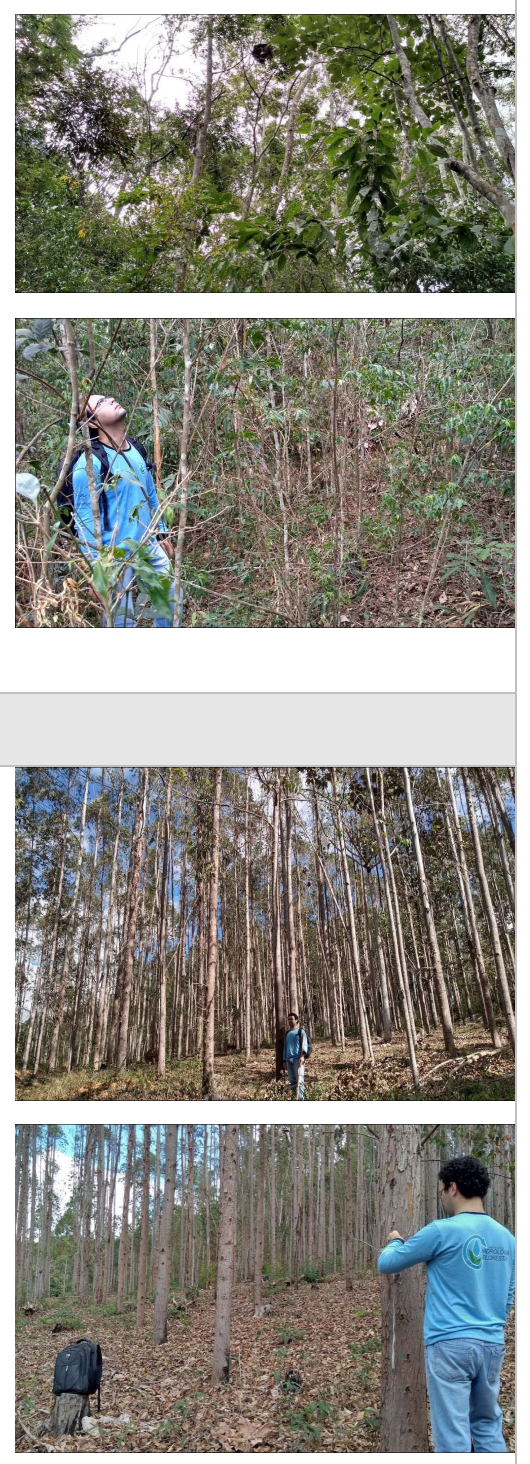
Os teores de umidade dos solos foram monitorados com amostras compostas deformadas de solo nas profundidades de $0-10$ e $10-20 \mathrm{~cm}$, coletadas a cada sete dias em cada uma das áreas, entre os dias 19 de abril e 17 de maio de 2016, totalizando cinco semanas. A determinação da umidade do solo (U) foi pelo método termogravimétrico (equação 1), conforme Embrapa (1997), que consiste em pesar a massa de solo úmido $(\mathrm{Mu})$ e, em seguida, secá-lo em estufa a $105-110{ }^{\circ} \mathrm{C}$ por 24 horas e, logo após, determinar sua massa seca (Ms), conforme apresentado:

$\mathrm{U}(\%)=(\mathrm{Mu}-\mathrm{Ms}) / \mathrm{Ms} \times 100 \quad$ (Equação 1)

Em que: $\mathrm{U}=$ umidade do solo, em $\% ; \mathrm{Mu}=$ Massa do solo úmido, em g; Ms = Massa do solo seco em estufa, em $g$.

Os dados de umidade do solo foram submetidos à análise de variância. Quando ocorreram diferenças significativas pelo teste $\mathrm{F}$, foram realizadas comparações de médias através do teste Tukey $(\alpha=5 \%)$.

A matéria orgânica e as propriedades físicas do solo (textura, porosidade total, densidade de solo e densidade de partículas) foram determinadas com amostras compostas deformadas de solo nas profundidades de $0-10$ e $10-20 \mathrm{~cm}$, em cada uma das parcelas, devidamente acondicionadas encaminhadas para análise.

\section{RESULTADOS E DISCUSSÃO}

A classificação textural do solo na profundidade de $0-10 \mathrm{~cm}$ foi diferente nos três locais. Esta diferença não ocorreu na profundidade de 10-20 cm, com os solos apresentando textura argilosa (Tabela 2).

Os locais avaliados apresentaram valores similares de densidade de partículas, densidade do solo e porosidade total (Tabela 3). A densidade do solo e a porosidade total são os parâmetros físicos do solo mais afetados pela ação antrópica (JAKELAITIS et al, 2008; FERREIRA et al, 2010). O aumento da densidade do solo está diretamente relacionado ao aumento da porosidade total do solo que causa diminuição de macroporos e aumento de microporos, dificultando a infiltração de água e aumentando os riscos de erosão hídrica (HOREL et al., 2015; NETO et al., 2017). No presente estudo, os três locais avaliados apresentarem solos com valores similares de porosidade total, porém podem apresentar distintas proporções de micoporosidade e macroporosidade.

Tabela 2: Análise textural dos solos sob os diferentes tipos de cobertura vegetal presentes na bacia hidrográfica do Ribeirão São Bartolomeu, em Viçosa, MG. Onde: $\mathrm{CV}=$ cobertura vegetal, $\mathrm{Prof}=$ profundidade, $\mathrm{Ag}=$ areia grossa, $\mathrm{Af}=$ areia fina, Sil $=$ silte, $\operatorname{Arg}=$ argila, tex $=$ textura.

\begin{tabular}{|c|c|c|c|c|c|c|}
\hline $\mathrm{CV}$ & $\begin{array}{l}\text { Prof } \\
(\mathbf{c m})\end{array}$ & Ag & $A \mathbf{f}$ & Sil & Arg & Tex \\
\hline \multirow{2}{*}{$\begin{array}{l}\text { Mata } \\
\text { nativa }\end{array}$} & $0-10$ & 0,331 & 0,209 & 0,072 & 0,387 & $\begin{array}{c}\text { Franco } \\
\text { argilo } \\
\text { arenoso }\end{array}$ \\
\hline & $10-20$ & 0,287 & 0,201 & 0,081 & 0,431 & Argila \\
\hline \multirow[t]{2}{*}{ Eucalipto } & $0-10$ & 0,268 & 0,168 & 0,061 & 0,503 & $\begin{array}{c}\text { Argila } \\
\text { arenosa }\end{array}$ \\
\hline & $10-20$ & 0,230 & 0,166 & 0,085 & 0,519 & Argila \\
\hline \multirow[t]{2}{*}{ Pastagem } & $0-10$ & 0,286 & 0,192 & 0,088 & 0,434 & Argila \\
\hline & $10-20$ & 0,289 & 0,189 & 0,081 & 0,440 & Argila \\
\hline
\end{tabular}

Fonte: Rodolfo Alves Barbosa, Lucas Jesus da Silveira, Ronan Soares de Faria.

O conteúdo de MOS foi maior para a mata nativa e menor para a pastagem, com 4,48 e 4,60 dag/kg e 3,36 e 2,99 dag/kg nas profundidades de $0-10$ e $10-20 \mathrm{~cm}$, respectivamente (Tabela 3). Alterações nos estoques de MOS podem ocorrer em virtude das práticas de manejo adotadas em diferentes coberturas vegetais (O'GREEN, 2012; WANG et al., 2013; SILVA et al., 2015). A MOS permite maior agregação e coesão das partículas de solo, tornando-o mais poroso e com maior capacidade de retenção de água, favorecendo o aumento na capacidade de infiltração (SANTOS e PEREIRA, 2013; JUNIOR et al., 2014). Segundo Khorramdel et al. (2013), o teor de 
MOS tende a um valor de equilíbrio, em áreas sob vegetação nativa. A área caracterizada neste estudo como mata nativa apresenta estágio médio de regeneração e os maiores valores de MOS, diferentemente da área de pastagem que, por estar submetida a inexistência de manejo e sujeita a queimadas, apresenta valores inferiores de MOS.

Tabela 3: Propriedades físicas e matéria orgânica dos solos sob diferentes tipos de cobertura vegetal na bacia hidrográfica do Ribeirão São Bartolomeu, em Viçosa, MG. Onde: $\mathrm{CV}=$ cobertura vegetal, prof $=$ profundidade, $\mathrm{Dp}=$ densidade de partícula, $\mathrm{Ds}=$ densidade de solo, $\mathrm{Pt}=$ porosidade total, MOS= matéria orgânica do solo.

\begin{tabular}{lccccc}
\hline C.V. & Prof. & Dp & Ds & Pt & MOS \\
\hline Mata & $0-10$ & 2,61 & 1,11 & 0,57 & 4,48 \\
nativa & $10-20$ & 2,62 & 1,13 & 0,57 & 4,60 \\
\hdashline Eucalipto & $0-10$ & 2,51 & 1,05 & 0,58 & 4,23 \\
& $10-20$ & 2,51 & 1,03 & 0,59 & 4,35 \\
\hdashline Pastagem & $0-10$ & 2,63 & 1,13 & 0,57 & 3,36 \\
& $10-20$ & 2,60 & 1,15 & 0,56 & 2,99
\end{tabular}

Fonte: Rodolfo Alves Barbosa, Lucas Jesus da Silveira, Ronan Soares de Faria,

O solo sob plantio de eucalipto apresenta valores de MOS próximos àqueles sob mata nativa, indicando que a deposição de serapilheira auxilia na incorporação de MOS, como observado em outros trabalhos (SILVA et al., 2011; FERNANDES et al., 2012; VIEIRA et al., 2014; NETO et al., 2017). Fernandes et al. (2012) encontraram maior teor de carbono orgânico do solo em plantios de eucalipto comparado a vegetação de cerrado preservada, atribuindo às práticas de manejo do solo o favorecimento da oxidação de matéria orgânica leve.

O solo sob pastagem apresentou variação brusca de umidade entre a segunda e quarta semana de monitoramento. $\mathrm{Na}$ segunda semana, a umidade do mesmo era de $10,3 \%$ e $10,7 \%$, aumentando para $16,9 \%$ e $16,2 \%$ na terceira semana nas profundidades de $0-10$ e $10-20 \mathrm{~cm}$, respectivamente, por ocasião de um evento chuvoso de $20 \mathrm{~mm}$. Na quarta semana, a umidade do solo sofreu redução acentuada, atingindo $12,5 \%$ e $13,5 \%$ nas profundidades de $0-10$ e $10-20 \mathrm{~cm}$, respectivamente. $\mathrm{O}$ solo sob a cobertura de híbrido de E. urophylla apresentou a menor variação de umidade ao longo do período avaliado, provavelmente em virtude das características da serapilheira sobre o solo, contribuído na retenção de água (Figura 3).

Figura 3: Precipitação acumulada (mm) e umidade média do solo (\%) sob os diferentes tipos de cobertura vegetal, nas profundidades de $0-10$ e $10-20 \mathrm{~cm}$, no período de 19 de abril a 17 de maio de 2016, em Viçosa, $\mathrm{MG}$, onde: $\mathrm{P}=$ pastagem; $\mathrm{M}=$ mata nativa e $\mathrm{E}=$ eucalipto.

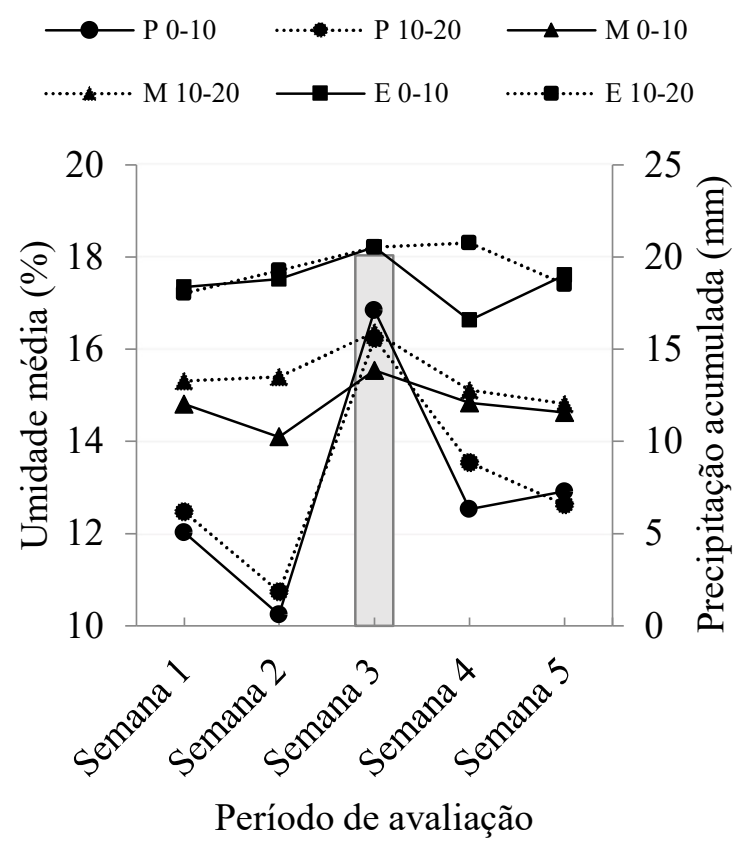

Fonte: Rodolfo Alves Barbosa, Lucas Jesus da Silveira, Ronan Soares de Faria.

A variação da umidade média do solo foi diferente entre as coberturas vegetais $(p<0,05)$, sendo que o solo sob eucalipto apresentou maior umidade média seguido da mata nativa e pastagem, respectivamente (eucalipto $>$ mata nativa $>$ pastagem) (Tabela 4). A umidade dos solos sob plantio de eucalipto e mata nativa 
apresentaram menor variação comparadas ao solo sob pastagem

Tabela 4: Retenção média da umidade no solo em diferentes coberturas vegetais profundidades, em Viçosa, MG. Médias seguidas por uma mesma letra, em cada coluna, não diferem estatisticamente (Tukey, $\mathrm{p}>0,05$ ).

\begin{tabular}{cccc}
\hline $\begin{array}{c}\text { Coberturas } \\
\text { vegetais }\end{array}$ & $\begin{array}{c}\text { Profundidade } \\
0-10 \mathrm{~cm}\end{array}$ & $\begin{array}{c}\text { Profundidade } \\
10-20 \mathrm{~cm}\end{array}$ \\
\hline Eucalipto & $17,46 \mathrm{a}$ & $17,77 \mathrm{a}$ \\
Mata Nativa & $14,78 \mathrm{~b}$ & $15,40 \mathrm{~b}$ \\
Pastagem & $12,91 \mathrm{~b}$ & $13,12 \mathrm{c}$ \\
\hline
\end{tabular}

Fonte: Rodolfo Alves Barbosa.

A cobertura do solo afeta sobremaneira a capacidade de infiltração de água, interferindo na disponibilidade de água para as plantas (VENKATESH et al., 2011; ZHANG et al., 2016; GUADAGNIN et al., 2018). De igual maneira, a densidade de plantas (NETO et al., 2017) e as práticas de manejo (SILVA et al., 2011) interferem na dinâmica da distribuição da água no perfil do solo.

Perdas de água por escoamento superficial foram reduzidas sob a cobertura de floresta nativa devido a diversidade de espécies e presença de serapilheira que contribuem na retenção de água no solo. A vegetação nativa preservada apresenta as condições necessárias para a retenção de água no solo e podem variar a precipitação efetiva (LORENZON et al., 2015; TONELLO; DIAS, 2018). A floresta nativa alterou a dinâmica da água interferindo na água que chega ao solo. A interceptação das chuvas pelas copas das árvores é maior em florestas em estágio avançado de regeneração do que em estágio inicial de regeneração (FREITAS et al., 2016).

O plantio de eucalipto apresentou maior capacidade de retenção de umidade no solo em razão das práticas de manejo adotadas e da ocasião da coleta das amostras
(5 anos após o plantio), no qual a cobertura do solo pela serapilheira facilita a infiltração e percolação de água. Sun et al. (2018) observaram maior capacidade de retenção de umidade do solo sob o plantio de E. urophylla comparado com outras culturas, no período de 2008-2013, verificando maior consumo de água pela planta no período inicial, ocorrendo uma gradual redução em estágios mais maduros, reduzindo também a perda de sedimentos por escoamento superficial. Almeida et al. (2009) observaram maior consumo de água de água em povoamento de E. grandis aos três anos de idade, propiciando redução no teor de água no solo. Os mesmo autores também relataram a redução do consumo após esta idade até aos seis anos, proporcionando a infiltração de água no solo.

A cobertura de pastagem foi a menos eficiente na retenção de água subsuperficial, consequência da ausência de manejo e degradação da pastagem. Souza, 2011 observou maior umidade média do solo em locais com geoforma côncava comparada com a convexa para café, eucalipto, pastagem e mata nativa em Viçosa-MG. Filho et al., 2016 observou maior velocidade de infiltração 4 vezes mais rápido em floresta comparada com pastagem. Perdas de água, solo e nutrientes de pastagens degradadas no bioma Mata Atlântica são elevados, sendo necessária uma reavaliação do sistema de manejo de pastagens (JUNIOR et al, 2017). A adoção de práticas de manejo adequadas, com adição de adubação nitrogenada ou consorciadas com leguminosas proporcionando aumento de mesoporos no solo, favorecendo a infiltração e a capacidade de suporte (VASQUES et al., 2019).

A colheita florestal realizada em plantios de eucalipto promove alteração nos processos hidrológicos na bacia que está inserida, geralmente é realizado o corte raso e a manutenção dos resíduos de cascas e folhas no local, aumentando a cobertura do solo, favorecendo a infiltração e o crescimento de brotações na segunda 
rotação de plantio (FRANÇA, 2017). Almeida et al., (2016) avaliaram o efeito da colheita total e parcial $(30 \%)$ na hidrologia de uma bacia com plantio de E. saligna comparados com uma bacia coberta por pastagem, e verificaram que o escoamento superficial variou de 7 a 13\% para a bacia com plantios florestais e $28-29 \%$ para a bacia coberta por pastagem, observaram também que houve um aumento do escoamento superficial em $23-24 \%$ para na colheita total e $17 \%$ na colheita parcial e aumento também no escoamento da área de pastagem para $32-44 \%$ devido o aumento da precipitação, mostrando menor capacidade de infiltração de água no solo na bacia coberta por pastagens. No presente estudo não foi observado o efeito da colheita na retenção de umidade, sendo necessário aumentar o tempo de avaliação.

A variação de umidade do solo pode ser atenuada com coberturas vegetais mais bem manejadas (JARDIM e BURSZTYN., 2015; RICHARDS et al., 2015), contribuindo no fornecimento de água para a população no período de estiagem (ALVARELI JUNIOR, 2014).

\section{CONCLUSÕES}

A umidade do solo é variável com a cobertura vegetal existente, assim como as práticas de manejo.

Condição inadequadas do manejo da pastagem pode ter prejudicado no conteúdo de matéria orgânica do solo, reduzindo a capacidade de manutenção de umidade no solo.

Plantios de eucalipto, quando submetidos a práticas adequadas de manejo e em estágio mais avançados de desenvolvimento, favorecem o incremento de matéria orgânica no solo, aumentando a capacidade de absorver e manter maior quantidade de água, podendo favorecer o fornecimento de água em bacias hidrográficas.

\section{AGRADECIMENTOS}

\author{
À Capes, ao CNPq e à FAPEMIG \\ pelo financiamento.
}

\section{REFERÊNCIAS}

\begin{abstract}
ALVARELI JUNIOR, S. Strategic
Environmental Assessment: aplication potential to the watershed of São Bartolomeu river, Viçosa - MG. 2014. 62 f. Dissertação (Mestrado em Ciência Florestal), Universidade Federal de Viçosa, Viçosa, 2014.
\end{abstract}

ALVARES, C. A.; STAPE, J. L.; SENTELHAS, P. C.; GONÇALVES, J. L.M.; SPAROVEK, G. Köppen's climate classification map for Brazil.

Meteorologische Zeitschrift, v. 22, n.6, p.711-728, 2013. DOI: 10.1127/09412948/2013/0507 Disponível em: em: https://www.schweizerbart.de/papers/metz/d etail/22/82078/Koppen s climate classifica tion map for Brazil. Acesso em $19 \mathrm{de}$ agosto de 2019.

\section{ALMEIDA, A. C.; SOARES, J. V.; LANDSBERG, J. J.; REZENDE, G. D. Growth and water balance of Eucalyptus grandis hybrid plantation in Brazil during a rotation for pulp production. Forest \\ Ecology and Management, v.25, p.10-21, 2007. Disponível em: https://doi.org/10.1016/j.foreco.2007.06.009} Acesso em 5 de maio de 2019.

ALMEIDA, A. C.; SMETHURST, P.; SIGGINS, A.; CAVALCANTE, R. B. L.; BORGES JR, N. Quantifying the effects of Eucalyptus plantations and management on water resources at plot and catchment scales Hydrological Processes, v.30, n.25, 2016. Disponível em: https://doi.org/10.1002/hyp.10992 Acesso em 10 de maio de 2019.

ANA, Agência Nacional das Águas. Encarte especial sobre a crise hídrica. Conjuntura 
dos recursos hídricos no Brasil, Informe 2014, 2015.

ARNELL, N. W.; GOSLING, S. N. The impacts of climate change on river flow regimes at the global scale. Journal of Hydrology, v.486, p.351-364, 2013.

Disponivel em: https://doi.org/10.1016/i.jhydrol.2013.02.010 Acesso em 02 de abril de 2019.

BARBOSA, S. G.; SPLETOZER, A. G.; ROQUE, M. P. B.; NETO, J. A. F.; DIAS, H. C. T.; RAMOS, M. P.; BONILLA, M. A. C.; RIBEIRO, W. S.; CRUZ, R. A.; ZANUNCIO, J. C. Geotechnology in the analysis of forest fragmentsin northern Mato Grosso, Brazil. Scientific Reports, v.8, 2018. Disponível em: https://doi.org/10.1038/s41598-018-22311-y Acesso em 02 de abril de 2019.

BERTOL, BARBOSA, F. T.; BERTOL, C.; LUCIANO, R. V. Water infiltration in two cultivated soils in Southern Brazil. Revista Brasileira de Ciência do Solo, v.39, p.573588, 2015. Disponível em: http://dx.doi.org/10.1590/01000683rbcs2 0140304 Acesso em 12 de maio de 2019.

BEUTLER, A. N.; CENTURION, J. F.; SOUZA, Z. M.; ANDRIOLI, I.; ROQUE, C. G. Retenção de água em dois tipos de Latossolos sob diferentes usos. Revista Brasileira de Ciência do Solo, p. 829-834, 2002. Disponível em:

http://dx.doi.org/10.1590/S010006832002000300029 Acesso em 11 de maio de 2019.

CARVALHO, D. F.; CRUZ, E. S.; PINTO, M. F.; SILVA, L. D. B.; GUERRA, J. G. M. Características da chuva e perdas por erosão sob diferentes práticas de manejo do solo.

Revista Brasileira de Engenhara Agrícola e Ambiental, v. 13, n.1, p.3-9, 2009.

Disponível em:

http://dx.doi.org/10.1590/S141543662009000100001 Acesso em 15 de março de 2019.
DIAS, L. C. P.; PIMENTA, F. M.; SANTOS, A. B.; COSTA, M. H.; LADLE, R. J. Patterns of land use, extensification, and intensification of Brazilian agriculture. Global Change Biology, v. 22, n. 8, p. 2887-2903, 2016. Disponível em: https://doi.org/10.1111/gcb.13314 Acesso em 12 de fevereiro de 2019

DIAS-FILHO, Moacyr Bernardino. Diagnóstico das pastagens no Brasil. Embrapa Amazônia Oriental-Documentos (INFOTECA-E), n. 402, 36 p., 2014.

EMBRAPA - Empresa Brasileira de Pesquisa Agropecuária. Manual de métodos de análises de solo. Centro Nacional de Levantamento e Conservação do Solo. Rio de Janeiro: Embrapa Solos. 1997. 212p.

FAO, Food and Agriculture Organization. The state of word's land and water resources for food and agriculture. Managing systems at risk, ONU, 308p., 2011.

FAO, Food and Agriculture Organization. Status of the word's soil resources. Chapter 12, Regional assessment of soil changes in Latin America and Caribbean, ONU, 38p., 2015.

FERNANDES, M. M.; CARVALHO, M. G. C.; ARAÚJO, J. M. R.; MELO, F. R.; SILVA, C. A.; SAMPAIO, F. M. T.; LOBATO, M. G. R. Matéria orgânica e biomassa microbiana em plantio de eucalipto no Cerrado Piauiense. Floresta e Ambiente, v. 19, n. 4, p. 453-459, 2012. Disponível em: http://dx.doi.org/10.4322/floram.2012.061

FERREIRA, R. M.; TAVARES FILHO, J.; FERREIA, V. M. Efeitos de sistemas de manejo de pastagens nas propriedades físicas do solo. Revista Brasileira de Ciências Agrárias, Londrina, v. 31, n. 4, p. 913-932, out./dez., 2010. 
FIGUEIREDO, L. T. M.; SOARES, C. P. B.; SOUZA, A. L.; MARTINS, S. V.

Alterações florísticas em uma Floresta Estacional Semidecidual no município de Viçosa, MG, entre 1994 e 2008. Floresta, v.43, n.2, p.169-180, 2013. Disponível em: http://dx.doi.org/10.5380/rf.v43i2.28869

Acesso em 15 de março de 2019.

FILHO, E. P. S. Velocidade de infiltração em área pastagem degradada e floresta natural no município de Porto Velho (RO).

Confins, v.29, n.29, 2016.

FRANÇA, J. S. Preparo do solo para eucalipto em segunda rotação: propriedades físicas, químicas e crescimento inicial. 2017, 109f. Dissertação (Mestrado em Ciência do Solo) -Universidade Federal de Santa Maria, Santa Maria.

FREITAS, J. P. O.; DIAS, H. C. T.; SILVA, E.; TONELLO, K. C. Net precipitation in a semideciduous forest fragment in Viçosa city, MG. Revista Árvore, v.40, n.5, p.793801, 2016. Disponível em: http://dx.doi.org/10.1590/010067622016000500003 Acesso em $01 \mathrm{de}$ maio de 2019.

GASHAW, T.; TULU, T.; ARGAW, M.; WORQLUL, A. W.; TOLESSA, T. Estimating the impacts of land use/land cover changes on Ecosystem Service Values: The case of the Andassa watershed in the Upper Blue Nile basin of Ethiopia.

Ecosystem Services, v.31, p. 219-228, 2018. Disponível em: https://doi.org/10.1016/j.ecoser.2018.05.001 Acesso em 10 de fevereiro de 2019.

GEROY, I. J.; GRIBB, M. M.; MARSHALL, H. P.; CHANDLER, D. G.; BENNER, S. G.; MCNAMARA, J. P. Aspect influences on soil water retention and storage. Hydrological Processes, v. 25, n. 25, p. 3836-3842, 2011. Disponível em: https://doi.org/10.1002/hyp.8281 Acesso em:12 de março de 2019.
GUADAGNIN, C. A., SCHÖFFEL, E. R., CASALINHO, H. D., BACIC, I. L. Z., VEIGA, M. Hydro-physical properties of three soils conducted under no-tillage, minimum cultivation and perennial pasture. Revista Scientia Agraria, v.19, n.1, p.124131, 2018. Disponível em: ttp://dx.doi.org/10.5380/rsa.v19i1.54841. Acesso em 05 de agosto de 2019.

HOREL, Á.; TÓTH, E.; GELYBÓ. G.; KÁSA, I.; BAKACSI, Z.; FARKAS, C. Effects of Land Use and Management on Soil Hydraulic Properties. Open

Geosciences, v.7, n.1, p.11-24, 2015. Disponível em: https://doi.org/10.1515/geo2015-0053 Acesso em 12 de fevereiro de 2018.

HUANG, X.; SHI, Z.; FANG, N.; LI, X. Influences of land use change on baseflow on mountainous watersheds. Forests, v.7, 2016. Disponível em: DOI:

10.3390/f7010016. Acesso em 20 de novembro de 2018.

IPCC, Intergovernmental Panel on Climate Change. Climate change 2014: impacts, adaptation, and vulnerability. Cambridge University Press, Cambridge, United Kingdom and New York, NY, USA, 1132 pp, 2015.

JAKELAITIS, A.; SILVA, A. A. DA; SANTOS, J. B. DOS; VIVIAN, R.

Qualidade da camada superficial de solo sob mata, pastagens e áreas cultivadas. Revista Pesquisa Agropecuária Tropical, v. 38, n. 2, p. 118-127, 2008.

JARDIM, M. H., BURSZTYN, M. A. Payment for environment services in water resources management: the case of Extrema (MG), Brazil. Engenharia Sanitária e Ambiental, v. 20, n. 3, p. 353-360, 2015. Disponível em: DOI http://dx.doi.org/10.1590/S1413$\underline{41522015020000106299}$ Acesso em $10 \mathrm{de}$ maio de 2019. 
JUNIOR, G. F. S.; CORÁ, J. E.; LAL, R. The effects of land use and soil management on the physical properties of an Oxisol in Southeast Brazil. Revista Brasileira de Ciência do Solo, v. 38, n. 4, p. 1245-1255, 2014.

JUNIOR, P. R. R.; ANDRADE, F. V.; MENDONÇA, E. S.; DONAGEMMA, G. K.; FERNANDES, R. B. A.; BHATTHARAI, R.; KALITA, P. K. Soil, water, and nutrient losses from management alternatives for degraded pasture in Brazilian Atlantic Rainforest biome. Science of The Total Environment, v. 583, p.53-63, 2017. Disponível em: https://doi.org/10.1016/j.scitotenv.2016.12.1 $\underline{87}$ Acesso em 2 de abril de 2019.

KHORRAMDEL, S.; KOOCHEKI, A.; MAHALLATI, M.N.; KHORASANI, R.; GHORBANI, R. Evaluation of carbon sequestration potential in corn fields with different management systems. Soil \& Tillage Research, v.133, p.25-31, 2013. Disponível em:

https://doi.org/10.1016/j.scitotenv.2016.12.1 $\underline{87}$ Acesso em 07 de agosto de 2019.

KÖPPEN, W. Versuch einer Klassifikation der Klimate, vorzugweise nach ihren Beziehungen zur Pflanzenwelt.

Geographiche Zeitschrift. v. 6, n. 11. H, p. 593-611, 1900.

LEI, C.; ZHU, L. Spatio-temporal variability of land use/lad cover change (LULCC) within the Huron River: Effects on strem flows. Climate Risk

Management, v.19, p.35-47, 2018.

Disponível em: doi.org/10.1016/j.crm.2017.09.002 Acesso em 12 de março de 2019.

LORENZON, A.S. L.; DIAS, H. C. T.; TONELLO, K. C. Escoamento superficial da água da chuva em um fragmento florestal da mata atlântica. Revista Brasileira de Agropecuária Sustentável, v.5, n.1, 2015. Disponível em: https://doi.org/10.21206/rbas.v5i1.316

Acesso em 02 de maio de 2019.

MARCHINI, D.; LING, T. C.; ALVES, M. C.; CRESTANA, S.; FILHO, S. N. S.; ARRUDA, O. G. Matéria orgânica, infiltração e imagens tomográficas de Latossolo em recuperação sob diferentes tipos de manejo. Revista Brasileira de Engenharia Agrícola e Ambiental, v.19, n.6; p.574-580, 2015. Disponível em: http://dx.doi.org/10.1590/18071929/agriambi.v19n6p574-580. Acesso em 12 de maio de 2019.

NETO, J. O. M.; MELLO, C. R.; SILVA, A. M.; MELLO, J. M. Temporal stability of moisture under effect on three spacing in a eucalyptus stand. Acta Scientarium Agronomy, v.39, n.3, 2017. Disponível em: http://dx.doi.org/10.4025/actasciagron.v39i3 .32656 Acesso em 12 de maio de 2019 .

NYAMADZAWO, G.; NYAMUGAFATA, P.; WUTA, M.; NYAMUGAFATA, P.; WUTA, M.; CHIKOWO. Infiltration and runoff losses under fallowing and conservation agriculture practices on contrasting soils, Zimbabwe. Water SA, v. 38, n. 2, p. 233-240, 2012. Disponível em: http://dx.doi.org/10.4314/wsa.v38i2.8AJOL Acesso em 05 de setembro de 2017.

OLIVEIRA, A. R. F.; ARAUJO, L. C.; LUDLKIEWICZ, M. G. Z.; ZAGATO, L. Q. D.; GALINDO, F. S.; MARUNO, T. C. Produtividade, composição morfológica e quimio-bromatológica do capim-marandu consorciado com sorgo forrageiro para renovação de pastagem degradada no cerrado. Cultura Agronômica, v.26, p.6981, 2017.

O'GREEN, A. T. Soil Water Dynamics. What are the relationships between soil moisture storage, soil water flow, and soil properties? Nature Education Knowledge, v.3, p.6-12, 2012. 
RICHARDS, R. C.; REROLLE, J., ARONSON, J.; PEREIRA, P. H.; GONÇALVES, H.; BRANCALION, P. H.

$\mathrm{S}$. Governing a pioneer program on payment for watershed services: Stakeholder involvement, legal frameworks and early lesson from the Atlantic Forest of Brazil. Ecosystem Services, v.16, p.23-32, 2015. Disponível em:

https://doi.org/10.1016/j.ecoser.2015.09.002 Acesso em 10 de setembro de 2016.

ROCHA-JUNIOR, P. R..; DONAGEMMA, G. K.; Andrade, F. V.; Passos, R. R.; BALIEIRO, F. C.; MENDONÇA, E. S.; RUIZ, H. A. Can soil organic carbon pools indicate the degradation levels of pastures in the Atlantic Forest biome?. Journal of Agricultural Science (Toronto), v. 6, n. 1, p. 84-95, 2014.

ROMANOVSKI, Z. Morfologia e aspectos hidrológicos da microbacia Rua Nova, Viçosa-MG, para fins de manejo. 2001. 99p. Mestrado em Ciência Florestal, Universidade Federal de Viçosa.

SANTOS, J.N.; PEREIRA, E.D. Carta de susceptibilidade a infiltração da água no solo na sub-bacia do rio Maracanã-MA. Cadernos de Pesquisa, São Luís, v. 20, n. especial, julho 2013.

SCHIELEIN, J.; BÖRNER, J. Recent transformations of land-use and land-cover dynamics across diferente deforestation frontiers in the Brazilian Amazon. Land Use Policy, v.76, p.81-94, 2018. Disponível em:

https://doi.org/10.1016/j.landusepol.2018.04 .052 Acesso em 05 de maio de 2019.

SILVA, M. A.; SILVA, M. L. N.; CURI, N.; AVANZI, J. C.; LEITE, F. P. Sistemas de manejo em plantios florestais de eucalipto e perdas de solo e água na região do Vale do Rio Doce, MG. Ciência Florestal, v. 21, n. 4, p. 765-776, 2011.
SOUZA F. S. Dinâmica hídrico-térmica e perdas de solo e água: influência do uso e geoforma do solo. 2011. 99f. Tese de doutorado em Solos e Nutrição de Plantas, Universidade Federal de Viçosa, 2011.

SOUZA, F.C. Dinâmica da estrutura e do estoque de carbono da vegetação arbórea adulta em 20 anos, em floresta Secundária da mata atlântica. 2015. 78f. Tese (Doutorado em Ciência Florestal) Universidade Federal de Viçosa, Viçosa.

SOUZA-FILHO, P. W. M.; SOUZA, E. B.; JUNIOR, R. O. S.; JUNIOR, W. R. N.; MENDONÇA, B. R. V.; GUIMARÃES, J. T. F.; DALL'AGNOL, R.; SIQUEIRA, J. O. Four decades of land-use, land-cover and hyroclimatology change in the Itacaiúnas River watershed, southeastern Amazon. Journal of Environmental Management, v.167, p.175-184, 2016. Disponível em: https://doi.org/10.1016/j.jenvman.2015.11.0 39 Acesso em 07 de março de 2017.

SUN, D.; ZHANG, W.; LIN, Y.; LIU, Z.; SHEN, W.; ZHOU, L.; RAO, X.; LIU, S.; CAI, X.; HE, D.; FU, S. Soil erosion and water retention varies with plantation types and age. Forest Ecology and

Management, v. 422, p.1-10, 2018.

Disponível em:

https://doi.org/10.1016/j.foreco.2018.03.048 Acesso em 12 de março de 2019.

TÁRNIK, A.; IGAZ, D. Quantification of soil water storage available to plants in the Nitra River Basin. Acta Scientiarum Polonorum Formatio Circumiectus, v. 14, n. 2, p. 209, 2015.

TONELLO, K. C.; DIAS, H. C. T. Does exists some relationship between restoration and hydrology of forests ecosystems?

Agricultural Research \& Technology, v.13, n.8, 2018. Disponível em: DOI: 10.19080/ARTOAJ.2018.13.555894 Acesso em 15 de março de 2019. 
VASQUES, A. A. S.; MORAIS, E. G.; BENEVENUTE, P. A. N.; SILVA, L. C. M.; HOMEM, B. G. C.; CASAGRANDE. D. R.; SILVA, B. M. Improved management increases carrying capacity of Brazilian pastures. Agriculture,

Ecosystems and Environment, v.282, p.30-39, 2019. Disponível em: https://doi.org/10.1016/j.agee.2019.05.017 Acesso em 15 de setembro de 2019.

VENKATESH, B.; LAKSHMAN, N.; PURANDARA, B. K.; REDDY, V. B. Analysis of observed soil moisture patterns under different land cover in Western Ghats, India. Journal of Hydrology, v.397, p. 281-294, 2011. Disponível em: https://doi.org/10.1016/j.jhydrol.2010.12.00 6 Acesso em 12 de março de 2019.

VIEIRA, M.; SCHUMACHER, M. V.; ARAÚJO, E. F.; CORRÊA, R. S.;

CALDEIRA, M. V. W. Deposição de serapilheira e nutrientes em plantio de Eucalyptus urophylla x E. globulus. Floresta e Ambiente, v.21, n. 327-338, 2014.

Disponível em:

http://dx.doi.org/10.1590/2179-

8087.05391 Acesso em 12 de março de 2017.

WANG, C.; ZHAO, C.; XU, Z.; WANG, Y.; PENG, H. Effect of vegetation on soil water retention and storage in a semi-arid alpine forest catchment. Journal of Arid Land, v. 5, n. 2, p. 207-219, 2013.

Disponível em:

https://doi.org/10.1007/s40333-013-0151-5

Acesso em 13 de abril de 2019.

ZHANG, D.; LI, X.; ZHANG, F.; ZHANG, Z. S.; CHEN, Y. Effects on rainfall intensity and intermittency on woody vegetation cover and deep soil moisture in dryland ecosystems. Journal of Hydrology, v.543, p.270-282, 2016. Disponível em: https://doi.org/10.1016/j.jhydrol.2016.10.00 $\underline{3}$ Acesso em 14 de maio de 2019. 